\title{
The role of standards in the forensic examination of materials substances and products
}

\author{
(C) Anna A. Zavialova, ${ }^{1{ }^{+}}$and Vasily V. Zavialov ${ }^{2}$ \\ ${ }^{1}$ Moscow University of the Ministry of Internal Affairs of Russia named after V.Ya. Kikotya. \\ Akademika Volgina St., 12. Moscow, 117437.Russia.E-mail: achkasova79@mail.ru \\ ${ }^{2} 27$ Scientific Center of the Ministry of Defense of the Russian Federation. \\ Brigadirsky Lane, 13. Moscow, 105005. Russia.
}

*Supervising author; ${ }^{+}$Corresponding author

Keywords: analytical standards, forensic examination, drugs, psychotropic substances, food products, detection agents.

\section{Abstract}

This article discusses the need for standardization of forensic activities. The need for standards to create an effective mechanism for the transition to a new level of forensic technologies in our country is due to the fact that it is necessary to optimize the use of special knowledge in legal proceedings, the exclusion of a large number of possible errors of experts.

Expertise is of great importance in criminal cases, its importance cannot be overestimated. The reliability of the expert's conclusions, the completeness of his research, affects not only the correct legal qualification of the crime, but also the fate of the convicted person. The most common types of examinations of materials, substances and products are based on the use of standards, they are used on a par with devices and tools. Without them, it would be impossible to conduct a reliable forensic study. The use of standards in expert research is a necessary condition for compliance with the requirements of Federal Law No. 73-FZ of May 31, 2001 in terms of ensuring the scientific validity, objectivity and reproducibility of both the course of research, the results obtained, and those formulated on the basis of the expert's conclusions. At the same time, attention is drawn to the fact that the standardization of forensic activities should not limit the freedom of choice of methods and other tools provided for by the legislation of the expert when conducting a specific study. The process of producing expertise should remain creative, and the research itself should remain a scientific work in the full sense of the word. It is unacceptable to drive an expert into a strictly formalized framework and templates, since no standard can provide for all the nuances of conducting forensic examinations in specific criminal and administrative cases.

\section{References}

[1] A.V. Kokin. Standardization and accreditation as the perspective of development of judicial examination. News of the Tula state University. Economic and Legal Sciences. 2017. No.5. P.17-23. (russian)

[2] Zamaraeva N.A. On the role of standardization in improving forensic activities in the Russian Federation. Theory and practice of forensic examination. 2015. No.2(38). P.28-32. (russian)

[3] N. Sevgich. Standartization of forensic activities. Economy and life. 2017. [Electronic resource.] Link: https://www.eg-online.ru/article/344902/.

[4] Federal law of May 31, 2001 N 73-FZ «On state forensic activities in the Russian Federation". Assembly of legislation of the Russian Federation of June 4, 2001. №23 article 2291.

[5] I.M. Fitsev, V.K. Blokhin, G.K. Budnikov, N.A. Fitseva. Chemical-analytical diagnostics in the forensic examination of materials, substances and products. Factory laboratory. Diagnostics of materials. 2004. Vol.70. No.4. P.3-15. (russian)

[6] Federal law of 8 January 1998 No. 3-FZ «On narcotic drugs and psychotropic substances". "Assembly of legislation of the Russian Federation of 12 January 1998, No. 2, article 219.

[7] I.M. Fitsev, V.K. Blokhin, G.K. Budnikov. Chromatographic methods in forensic examination. Journal. analyte. chemistry. 2004. Vol.59. No.12. P.1289-1298. (russian)

[8] "Quantification of certain drugs by gas, liquid chromatography and UV spectroscopy. Methodical recommendations" (app. Standing Committee on drug control, Protocol No. 7/96-2004 of 24.11.2004). 